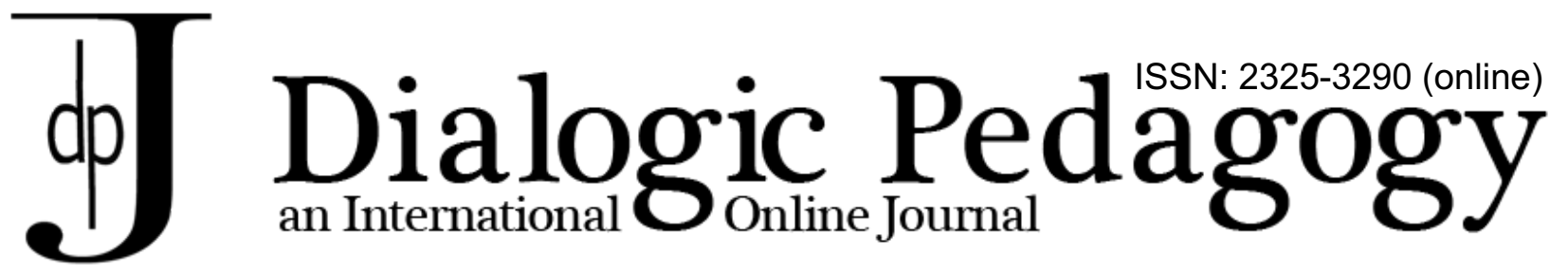

\title{
Ethical dilemmas in field placements: The experiences of social work students in Norway and possible implications for social work education
}

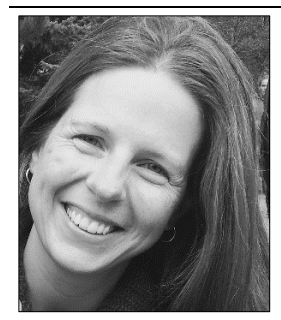

Heidi Lie Eriksen

University of Stavanger, Norway

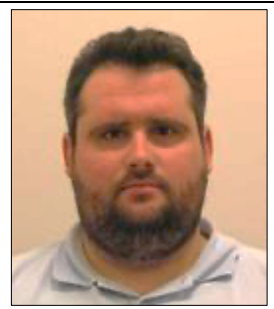

Mikhail Gradovski

University of Stavanger, Norway

\begin{abstract}
The study reported in this paper focuses on social work students' experiences of ethical challenges, including dilemmas, during their field placements. Moreover, drawing on dialogical approach and the results of the thematic analysis, the authors discuss what ethical dilemmas the students experience during their in-field practice, and what implications the handling of these ethical dilemmas can have for the organization of social work education. The findings that are reported in this article are the results of the analysis of six sets of data collected with the help of interviews. The interpretive framework used in this study is a dialogical approach. The research strategy has been a qualitative approach, and the data collection has taken place in semi-natural settings. The thematic analysis of the data lead to four major themes of ethical challenges that the students experienced in their field placements. The first theme concerns structural conditions on a macro level that the students were confronted with when in practice. The second theme is about ethical challenges due to the students' lack of knowledge and experience in the field. The third theme presents challenges in direct work with service users related to the students' awareness of values and perspectives. The fourth theme concerns ethical challenges that occurred when students interacted with others in the organizations where the field placements took place. We argue that due to the fact that the authorial agency of any learner consists of personal attitudes, goals, values, knowledge, competences, and skills, it is important to organize supervision activities in a way that allows discussions in free and fearless environments so that the student could learn and unlearn knowledge and skills. This means that in-field placements should be viewed as learning arenas for various types of knowledge and skills, including knowledge on themselves, and not just places where the students can gain only strictly professional practical knowledge and try out their theoretical knowledge.
\end{abstract}

Key words: Social work education, supervision, field placement, dialogical approach, thematic analysis, ethical dilemmas

Heidi Lie Eriksen is born in Lørenskog, Norway, but grew up in Bergen. She graduated as a social worker from Bergen University College in 2002 and finished a masters' degree in social work at the University of Stavanger in 2017. As a social worker Eriksen was employed by The County Governor of Rogaland in connection to legal guardianship and implementation of the UN Convention of the Rights of the Child. In addition, she has working experience as a social worker at the municipality level of the Norwegian Labour and Welfare administration and Social Services. This experience includes supervising social work students during their in-filed practice periods. As a researcher Eriksen is interested in the supervisory relationship that develops between social work students and field instructors. In April 2018 Eriksen started her PhD project that focuses on various aspects of supervisory relationship between supervisors and supervisees. 
Dr. Mikhail Gradovski is born in Minsk, Belarus. After graduation from the Norwegian University of Science and Technology in Trondheim as doctor rerum politicarum in 2008 with the thesis devoted to the Norwegian Dialogue Pedagogy, Gradovski has participated in both national and international research projects on doctoral supervision, professional supervision, use of dialogue in education, and mental skill development. Currently he is a main coordinator of an international EU Horizon2020 project that focuses on the development of PhD candidates' skills. He has supervised both postgraduate, graduate and undergraduate students. As a teaching practitioner he is using a dialogical approach based on an understanding both teacher and learner as partners with equal rights to make judgements on what is relevant, important and true. ORCID: https://orcid.org/0000-0003-3098-1447

\section{¿2\&}

\section{Introduction}

We define field placements as the "signature pedagogy" of social work and a part of field education in social work, where the intent of field education is to integrate the theoretical and conceptual contribution of the classroom with the practical world of the practice setting (CSWE, 2015, p. 12). The traditional way of following up the students during field placements has been through a one-to-one relationship between a social work student and a social worker at the organization where the field placement takes place. The oneto-one relationship has been claimed to have a great impact on how satisfied the students seem to be with their learning process during the placement (Bogo, 2008). Still, there seems to lack research concerning the dynamic within the relationship in general (O'Donoghue \& Tsui, 2015). Through field placements students are supposed to become more aware of their personal values through exercising social work directly with service users. It is therefore important that the students get supervision in this process to reflect upon professional and ethical issues (University of Stavanger, 2013, p. 6).

The personal values that the students have can conflict with both the professional andlor personal values of others, their supervisors, other colleagues and the service users. When different values conflict with each other this can result in ethical dilemmas for the students. Drawing on Heather Douglas' study (2014, p. 163), we define values as normative or emotive commitments people hold. These commitments may be tacit or explicit, and can concern a wide variety of things, from commitments to ethical principles, communal patterns of being, or even quality one wants to have in one's knowledge about the world. Different ethical principles in the code of ethics can, due to this understanding, also conflict with each other and result in ethical dilemmas for the students because they will have to prioritize between different ethical principles and give more importance to one over another of the principles (IFSW, 2018; Fellesorganisasjonen, 2019). In other words, even though the students themselves do not commit themselves to values that conflict with those of the social work profession, they can still end up experiencing ethical dilemmas because of the situations they experience, where different ethical principles can become relevant and it can be necessary to prioritize. Norwegian social workers and their colleagues with other educational backgrounds who are working in the public welfare sector are committed to follow both the Norwegian and the international code of ethics because the Norwegian association is a member organization of IFSW (Fellesorganisasjonen, 2019).

The first author of this article has both practical experiences as a social work student and had two field placements and as a field instructor providing supervision for social work students. These experiences have informed the importance of a fruitful relationship for the learning process of students, and on possible and worrying consequences in cases where ethical dilemmas are not discussed with the field instructors. This article reports some of the findings from a broader PhD project about the relationships between social work students and their field instructors during field placements. As the previous research does not seem 
to have been noticeably concerned with how ethical dilemmas are being handled within such supervisory relationships, we therefore ask: What ethical dilemmas the students experienced in their in-field placements, and what implications can the handling of these ethical dilemmas have for the organization of social work education?

\section{Theoretical part}

\section{Ethical dilemmas}

Proctor, Morrow-Howell \& Lott (1993) define an ethical dilemma in social work practice as an experience a social worker has when he or she cannot adhere to professional values or when adhering to one ethic requires behaving counter to another. Tallant and Ryberg (2000) distinguish between three types of situations when a social worker can experience an ethical dilemma: a situation where the social worker must choose the best moral course of action in a predicament from which there are two competing and equal moral choices, a situation when the decision-maker must choose the best moral course of action without knowing in advance the outcome of the decision, and a situation when the best moral choice may not be best for all the individuals involved in the predicament and, in fact, knowingly cause harm to one of the individuals.

Ethical dilemmas in social work can also be defined as one of the key elements of the ethics knowledge of the social work together with the value base of the social work professions, its relationship to practitioners' values; moral distress, injury, and courage; ethical decision-making; and ethics risk management (Reamer, 2019). Ethical dilemmas arise in situations when a professional social worker experiences conflicts between professional duties and obligations. To resolve an ethical dilemma means to decide what professional duty should take precedence in a conflict. Ethical dilemmas in social work are also connected to the ethical concepts and ethical decision-making models and strategies that can be used to resolve ethical dilemmas.

According to Reamer (2019), common ethical dilemmas in social work concern clinical practice, program design, agency administration, social policy, and relationships among practitioners. To help social workers to recognize and navigate through ethical dilemmas one has established ethical standards (Hardy, 2019). In Norway the first code of ethics for social workers was published in 1967, and Norwegian social workers were actively involved in the process of developing the international statements that were published in 1976 (Grønningsæter, 2013). Before 1967 the Norwegian social workers observed the American Code of Ethics (Lingås, 1993). The International Federation of Social Workers' (IFSW) Statement of Ethical Principles is one of the most recognized frameworks for social workers. The IFSW Statement of 2006 distinguishes between six different categories of standards: social worker's responsibility to the client, social worker's responsibility to the colleagues, social worker's responsibility in the practice setting, social worker's responsibility as a professional, social worker's responsibility to uphold the fidelity of the social work profession by involving themselves in research and service to the community, and social worker's obligation to promote social justice. In 2018 the standards on the social worker's use of technology in servicing the clients were added (Hardy, 2019).

Ethical dilemmas are directly connected to the value base of the social work profession. Although the core social work values vary internationally, and, at times, within nations and cultures, it is possible to distinguish between core social work values from the point of view of the concept of virtue (Reamer, 2019). The focal virtues in the virtue ethics include the following values and character traits: integrity, truthfulness, generosity, loyalty, sincerity, kindness, compassion, and trustworthiness. These focal virtues are linked to 
the core moral principles that constitute the moral foundation of professional practice: autonomy, nonmaleficence, beneficence, and justice (Reamer, 2019).

Supervision and the professional code of ethics are viewed as important tools for integrating the core values of social work into one's own practice. Moorhead \& Johnson (2010) show that inexperienced social workers learn quickly how to integrate theory into practice, especially, when it comes to ethical decision making. Sasson (2000) argues that the code of ethics gives room for interpretation when solving complicated dilemmas. However, it can also evoke conflict in the social worker as some principles in the code of ethics conflict with each other, and therefore, must be explored and justified when compared, and such a process will be influenced by the personal values and beliefs of the social worker. Banks (2005) investigated what situations students found ethically challenging and why. Her findings indicate that bad practice or oppressive practice of others in field placements was the most common ethical challenge for students. The two other ethically challenging aspects for the students were handling the power and responsibility of the worker and negotiating the power of the professional relationship.

Weinberg \& Banks (2019) write that social workers who in their educational programme have been trained to see moral injuries and to have integrity while working for the best of others, can experience frustration at the micro-level of the work with individuals due to political systems that challenge the situations of the service users. Contemporary political and structural systems seem to conflict with the values of the social work profession. This implicates that it is necessary to understand the connection between politics and ethics and to actively speak out against systems that make it difficult to practice the profession according to ethical principles (Weinberg \& Banks, 2019).

The code of ethics for social workers in Norway reflects external values, interests of the profession and political assumptions. From 2002 there has been introduced a perspective that is characterized by the feature that hallmarks related to the professional practice itself have been given attention as independent points. This can indicate that the professional practice can form a basis for and influence the code of ethics. This can be seen as a shift in understanding and an introduction of the principle that contextual aspects are given higher ethical status (Eide, 2008). Working efficiently is a value that fits with the political ideology of neoliberalism which influences the welfare organizations, but efficiency is not included in the value base of the social work profession (Swift, Gingrich \& Brown, 2016).

\section{Supervision: definition and its practice through the lenses of the dialogic authorial learning and authorial agency}

There are variations when it comes to the quality of the supervision students receive during field placements in Norway (the Norwegian Ministry of Education and Research, 2012, p. 73). Social work students have claimed that a good relationship with their supervisor is the key to successful learning in practice placements (Bogo, 2008). The study by Nordstrand (2017) of the Norwegian field instructors who supervised the students in the Norwegian Labour and Welfare Administration showed that the field instructors regarded quality control of students as their principal task (Nordstrand, 2017). The relationship between the social work students and their field instructors can influence how ethical dilemmas are handled.

Any supervision can be described as consisting of a product that a supervisee is supervised on, a supervisor and one or more supervisees. As for the period of the last ten years, we have found only three studies on supervision at the in-field placements of the social work students in Norway. The first study showed that field instructors who supervised social work students in NAV regarded quality controlling of students as their principal task (Nordstrand, 2017). The second study found that the power structure between the students and field instructors was levelled when social work students received parallel group 
supervision from social workers at the educational institution (in addition to the supervision provided by the field instructors), and this parallel supervision took place in a learning environment where it was allowed to make mistakes and explore different approaches (Nordstrand \& Skjefstad, 2019). The third study investigated how recently graduated social workers could contribute with quality and professional affiliation in the supervisory cooperation, and the authors highlights the importance of that supervisees from the beginning perceives themselves as independent and acting subjects and that the two that the dyad consists of together are going to create new insights (Søndenå \& Gradovski, 2017).

A study from New Zealand showed that the relationship between the field supervisors and social work students became unsatisfactory when the supervisors performed control function over their supervisees (Beddoe, 2011). This study's findings show that the relationship between the social work students and their field instructors can influence how ethical dilemmas are handled. Beddoe's findings are in accord with the study by Gradovski and Løkken (2015) where the field supervision of Norwegian preschool assistants was in focus. Their findings show that the main agent of influence on the subjective experiences of the assistants' reflection and learning experienced in supervision was the human factor, the cooperation and communication between the assistants and their supervisors. Findings from the studies by Nordstrand (2017) and Beddoe (2011) show that treating students at in-field practice placements by using mostly the means of instrumental control and poor quality of relationship between the supervisors and supervisees highlight the necessity to practice supervision using educational concepts where relationships between a supervisor and supervisees as a learning generating construct are acknowledged. A dialogic authorial learning is one of the educational concepts where the relationships between the supervisors and supervisees are considered to be a cornerstone behind any learning.

Supervision, according to Kadushin and Harkins (2003, p.123), can be understood as the critical examination of ideas and practice, even of one's own personality. Gradovski and Løkken (2015) define supervision as a setting for authorial learning consisting of five coordinates: time, space, interpersonal axiology, motivated guidance by supervisors and motivated participation by both supervisors and supervisees. The time can be viewed as a critical discussion or dialogue that involves testing of ideas and desires and discussing points of view and values; the space is the very culture with its epistemologies on its many levels that the participants exist in and represent. In order to experience the interpersonal axiology, there should be a mutual understanding between the supervisors and the supervisees that their values are formative in character and can and should be discussed and agreed upon. Both guidance and participation are issues that should be negotiated between the interlocutors.

In our view, a dialogic authorial learning is based on the assumptions that both supervisors and supervisees are learners with equal consciousness, i.e., their experience and points of view, no matter how little their experience is or naïve their points of view are, should be heard and reacted to. To use the dialogic learning concept when practicing supervision in the in-field placements means that values to both supervisors and supervisees are identified and negotiated. Learning that happens due to supervision is understood as an authorship. An authorship is defined by Eugene Matusov (2011) as a participant's bid for a unique creative contribution fully or partially recognized by a relevant community and by the participant $\mathrm{him} /$ herself (this recognition can be problematic, contested, and controversial at times). Learning is thus aimed at transformation of supervisees and supervisor's authorial agencies.

Matusov, von Duyke, and Kayumova (2016) define authorial agency as the transcendence of the given and write that our personal transcendence has to be recognised by relevant others and/or by the self, and this recognition calls for dialogicity and responsibility. Further, Matusov et al. (2016) write that a bid for social recognition of a person's transcendence of that which is culturally given transforms an individual's 
action into a personal deed, and the act of individual transcendence into a social event. This means that our authorial agencies lead to changes not only in knowledge and skills that we learn but also to changes in social relationships in our communities and society. The authorial agency of any learner consists of personal attitudes, goals, values, knowledge, competences, and skills. Any authorial agency is a dynamic entity that goes through changes, as the learner, the holder of the agency - thanks to the process of transcendence, and opportunities for responsivity and dialogicality-learns and unlearns new knowledge and skills.

\section{Method}

\section{Interpretive framework}

The interpretive framework of this study is a dialogical approach. Matusov, Marjanovic-Shane, and Gradovski (2019) define dialogic research epistemology as qualitative epistemology where the truth and understanding that comes as the result of the process of meaning making is highly subjective, and that each and every one has a right to his or her own subjective truths. Further, the subjectivity is defined as unique, unpredictable, creative, responsible, addressable, and responsive. The truth is authorial, personal, contextual, and unfinalizable. The truth has various depths of meaning, and is always calling for responsibility, interested, and disagreement-based. The very process of investigation is particular, contextual, and authorial. The findings include dialogic finalizing that can become a provocation for further critical dialogue, and they facilitate unlimited critical dialogue. Dialogue can be defined as the result of the communication between field instructors and students with different horizons of understanding when they are trying to comprehend each other's reality (Gradovski, 2012).

\section{Sampling}

As for the field placement that we focus on in this study, it takes place in the fourth semester of the bachelor program in social work and lasts five months. The selection of participants took place between December 2018 and January 2019, and it can be characterized as strategic. The reason for this is that the co-authors wanted to get insight into social work students' experiences with possible ethical dilemmas that were situated within the supervisory relationship in the students' unique field placements that formed part of their bachelor education in social work in a Norwegian university. Our selected sample is, therefore, information oriented. The respondents had to meet the following requirements: All the respondents were social work students (supervisees) who were supervised by qualified social workers (supervisors). Participation of both the supervisors and supervisees had to express their consent to participate in the study in writing. All the six supervisees that the sample of this data set consists of are Norwegian females aged between twenty and thirty years old.

\section{Data collection and analysis}

The data set analysed in this study consist of interviews with six students where they answered questions concerning the supervisory relationships and potential ethical challenges, including ethical dilemmas, that the students had experienced while staying in the field placements. Each student was interviewed twice. This means that altogether the data set consists of twelve interviews with six respondents. The first interview with each respondent took place at the beginning of the period of the field placement, and the second interview with each respondent took place at the end of the field placement. The collection of data took place in natural, social settings from January till May 2019. All the interviews were qualitative, semi-structured and individual, and they were conducted at the location of the field placement of each respondent. The interviews were all recorded by an audio recorder and thereafter transcribed. During the transcribing process the identities of the respondents, their supervisors, the 
locations where the field placements took place and other information that could cause people to be recognized were anonymized so that it would not be possible to identify the respondents, their supervisors, the locations where the field placements took place, the colleagues of the supervisors or the service users.

After all the interviews were transcribed, identities anonymized, and the transcripts themselves were checked for mistakes, the thematic analysis as described by Braun \& Clarke (2006) was used to analyse our data. Both co-authors have read the transcriptions several times and reflected upon potential codes and themes individually, and thereafter our subjective understandings were discussed. Although this process has been challenging and time consuming, we argue that it has improved the analysis and resulted in new insights.

We used the thematic analysis to identify themes within our data and to interpret various aspects of these themes. Social work students' ethical challenges, including ethical dilemmas, is the focus of our thematic analysis. The data collected was coded in order to answer our two research questions, and thus, a specific, analytic interest guided us in this analysis of the data set. In our analysis we followed the six phases of thematic analysis as these are described by Braun and Clarke (2006, p. 87).

These six phases consisted of first becoming familiarized with the data by reading the transcriptions thoroughly several times and by highlighting immediate ideas. Thereafter, we generated initial codes by finding interesting features of the data and then coded these in a systematic way within each data item and thereafter across the whole data set. Data that was relevant to each code was collated. Then we searched for themes, collated codes into potential themes and gathered all the data that was relevant to each potential theme. After this we reviewed the themes thoroughly and changes were made as we went deeper and deeper into the analysis. Finally, there were two main themes that were identified related to the ethical dilemma that the participants experienced during their field placements.

We checked whether the themes worked in relation to the coded extracts and the entire data set, and then generated a thematic "map" of the analysis. We thereafter defined and named the themes and did an ongoing analysis in order to refine the specifics of each theme, and the overall story that the analysis told. We generated clear definitions and names for each theme. Thereafter we produced the report for the analysis and chose a selection of compelling extract examples. We related back from the results of our analysis to the two research questions and to the literature and finally produced a scholarly report of the analysis.

\section{Validity and reliability}

The awareness of the participants regarding the appearance and significance of ethical dilemmas in their practice varied. When collecting the data, it was not expected that the participants should have a vocabulary to speak about ethical dilemmas in their practice. What we talked about in the interviews was therefore rather difficulties when executing their role at the field placement. As researchers we are aware that we are in the powerful position of defining the ethical dilemmas that the students experienced, and the presented results are thus our interpretations of what the students shared. We attempted to clearly state the theoretical assumptions that formed the scope of this research and to describe in detail the methods used to come to the presented conclusions. This has been important in order to strive for trustworthiness and to conduct research that would be possible to compare and evaluate for others, as well as to promote further research concerning the issues treated in this article (Braun \& Clarke, 2006, p. 80). The outer validity of our results extends only over the interviewed participants. Therefore, our findings are not automatically transferable to the experiences of other social work students. It can also be seen as a weakness that all the participants were young, white women with a Norwegian background, even though variation among the 
participants was something that we as researchers had hoped for. However, most social work students in Norway have the same characteristics as our participants and striving for more variation among the participants would have complicated the recruitment process. Hopefully, it will however be possible to generalize findings in an analytical meaning of the concept as it is described by Yin (2012, p. 177).

\section{Ethical considerations}

Ethical considerations have been made at all stages of this study. The students and their supervisors were clearly informed that their participation in the study did not have any relevance for the evaluation of the field placement or their relationships with the educational institution in any way. Likewise, they were informed that to withdraw from the study along the way would be unproblematic. Both co-authors had roles both as teachers for students in field placement and researchers at the University. To prevent potential ethical dilemmas because of the double role as both researchers and teachers for the same students and supervisors, our colleagues at the university made sure we were not given responsibility for students who met the criteria to participate in the study. A notification form of the data collection was submitted to The Data Protection Official in Norway (NSD) and it was subsequently by NSD.

\section{Results}

As the result of our thematic analysis, we found that the students experienced four major themes of ethical challenges in their field placements. The first theme concerns structural conditions on a macro level that the students were confronted with when in practice. The second theme is about ethical challenges due to the students' lack of knowledge and experience in the field. The third theme presents challenges in direct work with service users related to the students' awareness of values and perspectives. Finally, the fourth theme concerns ethical challenges that occurred when students interacted with others in the organizations where the field placements took place. As a result of our understanding of what an ethical dilemma is, we argue that out of these four ethical challenges only some of them ended up in becoming ethical dilemmas for the students. Thus, we will hereafter describe the four themes of ethical challenges that we found through our thematic analysis. After this presentation, we will introduce the ethical dilemmas that we discovered within the ethical challenges in the chapter of discussion.

\section{Ethical challenges related to structural conditions}

Structural conditions seemed to influence whether or not the students experienced ethical challenges when in practice. Through our analysis, we found that Elisabeth, Christina, Beate and Anne experienced ethical challenges related to such structural conditions on a macro level. When new learning situations came as a surprise for the students, the field instructors, probably due to several reasons, did not manage to structure the learning situations, and the students got less attention and support than what they needed. On some occasions, such lack of support indirectly created ethically challenging experiences for the students in this study. Still, the aim of this study has not been to investigate the structural conditions on a political or organizational macro level. Our focus has been the individual experiences. Thus, what we can say from our analysis is that students on some occasions did not get sufficient support according to their needs when being exposed to new learning situations. At times, and seen from the students' point of view, the field instructors had not been clear enough about what they expected from the students. We found that both lack of support and clarification led to the same consequence: the students did not know how to prepare themselves for tasks they had been assigned. This made the students feel insecure and confused about whether they had misunderstood something important, and they blamed themselves for not successfully coping with the tasks. It was from the service users' and the field instructors' reactions that the students perceived that they had failed tacit expectations. The students understood that they did not 
act as they were supposed to, yet, they did not know what the appropriate behaviour in the situations would have been.

The quote from Elisabeth below illustrates how she experienced being put in a situation that she did not know how to manage due to lacking support and explanation ahead.

Elisabeth: I had a case. I was not supposed to have that conversation because I had other plans. Then they got cancelled, then the field instructor said that I could take that conversation after all. And then I got so little time to prepare myself. And it was a comprehensive case that I kind of didn't understand what she needed help for, because she said that she just had a question about a decision or something. And I didn't have a clue what it was. And there I could almost not answer anything. I didn't have any overview. No, for instance, she said among other things that there was an electricity bill that hadn't been paid, but then she's got a decision for that, so then I didn't understand why it shouldn't have been paid. Ohm... And then she and her daughter had applied for a residence permit and I hadn't even got it that she'd applied for it, because I only looked at her decision and what she'd applied for, so then I couldn't answer that. And it wasn't very nice when I like sat there just opposite the service user and I'm supposed to be professional and feel that I'm supposed to give her answers, but when I don't have the overview over her whole situation it gets very difficult.

Christina often worked at the field-placement while one or both of her field instructors were not there. She described that the coordination between the two field instructors and the learning activities she was confronted with were not always well planned. Below she talks about how she all of a sudden experienced conducting a conversation with a service user and an interpreter without being able to prepare herself for the task that was completely new for her.

Christina: And then I was told I had to call my field instructor. I just; okey. Then he says: We're going to realize an interpreted conversation with the teenager. So you have to order an interpreter, you also have to talk to the teenager about that we're going to do this, we're going to.. and you have to inform the teenager why we're having this interpreted conversation. And I just; okay, fine. And then I went and talked to the teenager and then it didn't suit the teenager when we thought we'd have this interpreted conversation, so then I called my field instructor again and said kind of like: I think we should have it another day because this and that. Uh, and he just: Yeah, okay, but then we'll do that, I'll come up that day, so just order it! And then when the day came I thought that... I didn't really think that I was going to lead the conversation. I thought I was just going to participate in it. And then we call the interpreter, and then he (the field instructor) says: Yeah, just speak, you're the one doing it!

Beate expressed that she wanted to experience as much as possible during her field placement. She was therefore grateful that her field instructor had arranged for her to visit other institutions as well, and she went to these institutions by herself without knowing much about what was expecting her. Beate was left alone with service users whom she did not know from before. Since she had not been well prepared for these visits, she did not know how to handle the situations she was confronted with. The extract below illustrates the unexpected reaction she got from the service user when she suggested to organize an activity that the service user said that she liked.

Beate: And then I started kind of yes, what do you like to... Do you like playing games? Then she said yes, I do. Then I said: Do you like playing cards? Then she said: Yes, I think that's fun. Then I said: Would you like to play some now? No, I don't feel like it. Then I said: Okay... And then she said: 
It's because I don't know any. But then I said: But I can teach you if you want to. No, you don't have to. (...) It was kind of the first time anyone has said no to something that I have suggested.

At the end of the field placements it was expected that the students worked efficiently. Still, focusing on how to manage large amounts of cases was not something that the students felt that they had been trained to do at the educational institution. We found that the students expressed conflicts between the field instructors expectations of efficiency and the values of the social work profession about how to treat the service users with time and patience. The quote below illustrates how Anne experienced that she was not well prepared for the expectations towards her about working more efficiently. Still, the fact that Anne was not well prepared for the expectations concerning work efficiency is something that can be explained as a lack of preparation for such activities from the educational institution, and this is not something that can be explained as the result of the lack of preparation from the field instructors' side.

Anne: We've talked a lot about that in supervision too, related to this with efficiency then. And I mentioned that a little before, that the doctors and the psychologists they must know absolutely everything about the patient, whilst I really don't then, or the other social workers, because we've a little more to do with the social work issues. But I do know that if I've had a conversation, and I sense that the patient has liked very much to talk and has brought up things that I really hadn't thought we were going to talk about, then l've thought that it's good that he opens up or she opens up and that it's kind of nice if it can help then somehow. But.. so.. I should probably have had more time for that, maybe. But then that's not actually the task... In a way.. yes.. I don't really feel that we've talked that much about that to be honest, but maybe I slept in those classes... Yeah.. Because then we've rather had that.. yeah, you never know what's coming through the door, you never really know what direction the conversation takes, but it's important that you take the time or.. No, maybe I'm inventing a little, but that's at least how l've got the impression kind of related to social work and stuff.

\section{Ethical challenges due to the students' lack of knowledge and experience}

Through our thematic analysis, we found that limited work and life experiences created ethical challenges for the students. For us it became clear that Frida, Beate, Christina and Dina struggled because they lacked experienced and knowledge. The students were insecure when it came to how they were supposed to act out the social worker role and they struggled sorting out how they were going to create fruitful relationships with the service users. How to respect the boundaries of themselves and the service users, where to draw the lines between personal and professional identity, and ending the relationships with the service users were complicated issues for the students.

Frida was struggling with both boundary issues, learning how to assess the service users' behaviour, and learning to understand when it was necessary to end activities. She had experienced that the service user when in psychosis had scared her before and Frida therefore later was sensitive to when the service user could seem to be having a psychotic outbreak again. Frida could feel quite uncomfortable when being alone with the service user and she was uncertain about when she should step out of different situations.

Frida: I find it difficult to set up boundaries there because there you must consider a lot. And then she is listening to music and then she maybe starts dancing and sometimes the movements she makes... It can just become too much for me. Then she can get a little high and there is a risk of a psychosis. 
Beate sent text messages to the service users she worked with during the week to encourage them or show that she cared for them, even though the content of the messages did not have anything to do with the services Beate provided to the service users. Nor had she spoken to the other social workers at the placement about what they thought of contacting the service users outside of the agreements that they had. Beate had just developed her own practice without consulting her field instructors or other colleagues about it.

A fear of invading the private life of the service users was perceived, and it was difficult for the students to know what they could talk to the service users about and not. It was necessary with guidance in this matter. Christina mentioned a young unaccompanied minor who according to his residence permit was gay, and he was living with other teenagers who spoke condescendingly about people with a sexual orientation that was not heterosexual. The student assumed that the young man had a difficult time, but she was not sure whether she should talk to the young man about the issue or not.

Christina: I haven't talked to him about it and I'm not sure if it's something that anyone else has discussed with him either. Because for a long time we were insecure about whether he knew that we knew about it. We've come to the decision that he must know about it since he got his residence because of it. However, he has also been very uncertain about it, and this is something that is very unsafe for him. So, because of that I haven't felt that I've been the one to talk to him about it.

Dina was aware of that she could risk meeting people she was familiar with in her practice because of her experience as a volunteer. She struggled reflecting upon what expectations these people might have towards her behaviour and how she would live up to these expectations. Still, she concluded with that she had different roles in different settings and that this was acceptable.

Dina: I have in a way understood that when I'm here, I'm at work, but when I'm not here, then I'm $m e$ in a way. So, if I run into them.. Because I' $m$ often at birthday parties or that kinds of things with these Kurds and they often bring along people who either are at the program or have been to the program or that sort of things. And then there's often talking about; yeah, I had this and that one as a counsellor and.. That kind of things.. But, I'm only myself in a way, but I don't go on about my coworkers or the organization in that way, since they're here. When it comes to that, yeah.. But.. So, I am myself. Yeah.. I don't know how others do it or whether it's the correct way, but I believe it should be all right, because I'm not at work or in practice when I'm out there. The challenges might be that if I meet those service users at the office and they maybe meet another person than the one they met outside, how they will react upon that. But I think that if it occurs then one just have to explain then that now I'm working, kind of, and that was private. Well, one's the same, one is, but I'm really a little different when I'm at a Kurdish party then what I'm like when I'm sitting here in the office filling out an application form for social benefits. I actually am. For instance when I'm dancing there, then it strikes me: Oh, Lord! But, we're all humans so...

The students invested in developing good and fruitful relationships with the service users they got involved in too, and it was difficult for them imagining that these relationships would end in a relatively short period of time. The thought of ending the relationships with the service users was difficult for the students and there seemed to be a dependency to the relationships. Frida struggled with the reaction she got from the service user she worked with when the ending of the placement was coming up. 


\section{Ethical challenges arising from the awareness of values}

All the six students in this study experienced ethical challenges as they became better aware of their own values and perspectives. The students struggled to maintain their professional integrity and respect diversity among the service users at the same time. Even though the students tried to adjust themselves to the needs of the service users when they practiced social work, their efforts were not always appreciated. Despite of the students' good intentions, they sometimes faced the service users' rejections, unwillingness, lack of engagement or got frightening reactions. It was difficult for the students to accept that things could go wrong when they did everything they could to help. When experiencing these disappointments or facing frightening reactions, the students became aware of the values that they needed to work on too. Our findings show that the students became more aware of their own values and perspectives from practicing social work directly with service users and later reflecting about prejudices and worries in supervision with their field instructors. Sometimes the students realized that they had had unrealistic hopes for the lives of others. With the following examples we will hereafter illustrate this.

Dina worked with a single mother who came to Norway a few years ago as a refugee with her five children. The child welfare officers were worried about the children and the lack of attention from their mother. Dina and her field instructor at first disagreed upon whether their guidance and support would be enough to help the mother with improving the level of care of the children. Dina was at first optimistic, but then she became frustrated and realized that it would not be possible for the mother, the service user, to cope with her responsibilities on the level required by the child welfare officers. Through the work with this service user, Dina experienced a confrontation between her own values and the values of the mother.

Dina: No, I get a little like; oh, make it! Yeah... I want her to do well. Then it's a little hopeless in a way, that you see that it... Yeah, I don't know if it's going to happen. The economy and the children and the school and the child welfare and just like... when she can't read and write herself, how difficult will it be when the children are going to start at school and will help them to do their homework and yeah... And the economy as well... Then she's said that she'd like even more children. Yeah... And cannot really take care of the ones she has. No, because that... We asked her about that, but I think it was just because five were not enough. She wanted even more, but then we said: Don't think that's so smart because it's difficult to have many children in Norway because it's expensive and challenging. All the children are going to recreational activities and they're going to do this and that, so we tried to explain her that, then. But she doesn't always want to listen when we tell her stuff.

The students were afraid of that potentially aggressive service users in different situations could harm them, but they seemed to feel ashamed of these feelings. Frida worked with a service user who sometimes entered into a psychosis, and Frida had been hit by surprise by such an incident on her first day of the placement. This incident got a hold on her and made her feel insecure afterwards when she was alone with the service user. In the extract below Frida explains how she escaped from a situation that scared her and left the service user alone instead of handling the situation that arose.

Frida: That was the second time I was at work. I guess it was the Tuesday, so then I still was a little afraid of her, right. While I knew that I really didn't have any reason to be that. But then... She got some of the movements when she danced and sang as she got in the car and then I became like; okay, is this bad or just ordinary? So, then I was a little like... right... And then we sit behind the treadmill, right, because it can become too much stimuli with us and the music and the video and that. Yeah, and then she's walking on the treadmill and then she is singing and dancing a little bit in between and then she looked at me with that intense gaze and then I became afraid, so then... I told 
her ohm... I just need to go to the bathroom now and then at that exact time the other staff came, so then; okay...

When starting in practice, Anne was uncomfortable because she thought that she had negative stereotypes towards elderly in general. This was a problem since Anne had been assigned to work with elderly people during her field placement. After talking thoroughly about her stereotypes in supervision, Anne became aware of that her prejudices was rather about helping people in general with a specific task than towards the elderly in general.

Anne: I was a little like excited about what it was going to be like working with the elderly because I've worked as a summer substitute at a nursing home where I'm from when I... some years ago. And then I remember that... that I didn't like it that much. I thought that was a little difficult. But when I thought more about it then...and told my field instructors, then I realized that what I really didn't like was caring and that... I thought it was kind of uncomfortable. And then... I really think it is very interesting to talk and have conversations with the service users. So... I probably think that this image has changed a little really, that it... And that's been nice.

\section{Ethical challenges due to the interaction with others}

Anne, Beate, Dina, Elisabeth and Frida experienced ethical challenges due to working with others and staff members observing the practice of other staff members at the field placements. The staff had different educational backgrounds, and not everyone was necessarily social workers. The students reacted negatively to the way others spoke about the service users on specific occasions and that the service users in some situations were being treated differently than the students would have liked to be treated themselves. Whilst the students focused on their own behaviour and communication skills in contact with the service users, they also became aware that other employees at the field placements did not always act in accordance with what the students considered to be good social work practice. It was thus a contradiction between what the students considered as practicing good social work and what they observed of social work practice at the placements. Still, through our thematic analysis we found that the students often experienced it as difficult being critical towards the practice of others. The students had difficulties with criticizing the way others did their job. It was easier for them to copy what others did than saying what they meant should have been done in another way.

Elisabeth was taken by surprise because other employees at her placement in internal meetings spoke about the service users in what she saw as negative ways. Elisabeth stated that she would not have preferred that her colleagues had spoken about someone she cared for in the way that they talked about the service users.

Elisabeth: Of course, everyone is working together and is supposed to find the best solution. However, when they discuss a case it's like: Oh no, is it this one again, he has this and that kind of illness, and it's kind of patronizing and then I think: what if they had discussed someone we know?

Anne experienced that there was a contradiction between how she would have liked to be treated herself and how service users sometimes were being treated at her field placement. This happened to be the case when she realized that information was being withheld from a service user regarding changes in her medical doses, in order to prevent negative reactions that the staff would have trouble handling.

Anne: I remember once there was a discussion about a service user. She was taking a certain number of medications, and she didn't really know how much she was taking because the therapists 
hadn't told her, and they were kind of afraid to tell her because then it could get a little miserable, so then they just chose to say that in a way. And I am not sure that it was necessary either, but at the time I remember that I thought that it was the kind of thing one should inform any service user about. I thought about myself then, that I think l'd like to know it if it had been me.

Dina experienced that the social workers at her field placement helped the service users by doing different things for them instead of teaching them how they could fix things themselves. This was something that Dina reacted to because she had learned that it was important for people to play an active role in their own lives for many reasons.

Dina: I have observed a little and I do see that at the university we learn a lot about service users' participation, and it has not been service user participation to the same degree as I think that it could have been. No, because I think that if for instance a person turns up who is going to apply for social assistance... That he can fill out the application form himself, go into the internet himself and find it. That you guide the person instead of going into the internet yourself and filling out everything for him.

Frida experienced that her field instructor together with another social worker were following the guidelines too strictly in regard to one situation with a service user. This service user was denied a possibility to spend her own money on snacks that she wanted, because, according to the staff members, there was no need to buy more when she already had something similar at home. The situation was uncomfortable to witness for Frida because she observed that this tiny issue seemed to mean very much for the service user and thus Frida could not understand why these two staff members did not show more flexibility in the situation.

Frida: Then it was apparently only the staff member who was going to buy something, and the service user knew that when they went into the store. This happened on Friday, and when they were shopping for the Saturday evening because they too ate snacks with her, since it would have seemed strange if they hadn't done so. While in the store, the service user also wanted cheese doodles. However, the staff member replied that she still had some other crisps left at home from last time, and that there was another type of snack that was as home as well, so there was no need to buy new cheese doodles as she already had enough snacks at home. But the service user really wanted cheese doodles and became very sad because when the staff member said no. And there I don't really understand why they just couldn't allow her to buy these doodles.

Being critical was difficult for Elisabeth when she did not manage to understand the complexity of the situations she observed. In Elisabeth's citation below she shared her reflections about what it felt like when she was striving to become more critical.

Elisabeth: I thought it was hard in the beginning. And, we discussed that during the supervision session too, because my field instructor also said that I wasn't critical enough. I just understood everything as a truth and I was very aware of that myself, so I've tried to challenge myself a little bit on that. And especially when l've been with other employees in different departments, then l've kind of tried to be very outgoing. So, I feel that l've become more critical now at least compared to when I started, but I could have been even more so. I don't really know, but I don't manage to see the whole picture. I see what's at that point and then I think; yeah, but that sounds fine. And then I don't come up with that there are other and better possibilities. 
When Beate was given the responsibility for the service users who her field instructors normally were working with she found it hard to know whether she could exercise her role as a social worker in the same way as her field instructor used to do.

Beate: But l've been insecure, right, because she's originally Maria's (field instructor) service user, so whether I can push as much as Maria can push. Ohm... So, then I've been very insecure, but it turned out that I could then. Because I notice it in the service user when I talk to her if she's kind of receptive for me to push a little. Yeah, if she shows a little like ambivalence then, maybe it would have felt good, yeah, and then you push more. But if I notice in her voice when I talk to her on the phone one day that absolutely, absolutely not, then I don't push anymore then. But if I feel that she is showing a little like interest and if she additionally; oh, it feels so good that you're calling, that you care, all this right, then I am feeling like, okay, then I've got a small loophole, that maybe I can give in a little extra then. And it has turned out, several times, it has proven to work. So, then l've pushed, and l've come to her house and then she participates in all sorts of things, and then she becomes so grateful and happy.

\section{Summing up the ethical challenges experienced by students}

The students experienced ethical challenges due to structural conditions influencing the provided support in learning situations, the students' lack of knowledge and experience, the own awareness of values and how these conflicted with others, and finally, through interacting with others. Only some of these ethical challenges ended up in becoming ethical dilemmas for the students. Hereafter, the ethical dilemmas that we discovered within the ethical challenges will be presented and discussed against relevant theory about ethical dilemmas and previous research. Finally, we will reflect upon the implications our research might have for the education of future social workers.

\section{Discussion}

We have conducted a thematic analysis of ethical challenges that six social work students experienced during their in-field practice. We have found that the students experienced ethical challenges related to structural conditions at the field placements, lack of knowledge and experience, awareness of values and interaction with others. Only some of these ethical challenges can be categorized as ethical dilemmas. Proctor et al. (1993) define an ethical dilemma in social work practice as an experience a social worker has when he or she cannot adhere to professional values or when adhering to one ethical principle requires behaving counter to another. Tallant and Ryberg (2000) distinguish between three types of situations when social workers can experience ethical dilemmas: situations where the social workers must choose the best moral course of action in a predicament in which there are two competing and equal moral choices, situations when the decision-makers must choose the best moral course of action without knowing in advance the outcomes of the decisions, and situations when the best moral choice may not be best for all the individuals involved in the predicaments and, in fact, knowingly cause harm to one of the individuals. When interviewing the students, the concept "ethical dilemma" was not defined in order to avoid shaping the students' understandings of ethical dilemmas into our prejudices as researchers. It became clear that the students did not talk directly about ethical dilemmas. They rather talked about challenging or difficult situations they had experienced. There might be different reasons for why the students did not talk expressively about ethical dilemmas. They might not have been trained to identify ethical components of different cases they were working with, they might have little power at their field placements, or they might not have been delegated much responsibility during their practice and therefore might not have needed to make difficult decisions (Banks, 2005). To find out whether or not the different ethical challenges can be understood to be ethical dilemmas or not we will discuss whether or not professional values are impossible 
to adhere to, or whether there seem to be conflicting ethical guidelines in the different ethically challenging situations experienced by the students in our study.

\section{What ethical dilemmas did the students experience in their in-field placements?}

\section{Structural conditions}

The first category of ethical challenges that the students in our study experienced was related to structural conditions. It is well known that structural and political problems is an aspect that earlier has been found to negatively affect the practice of social workers (Banks, 2005). In this study we have identified students' challenges that occurred in situations where they noticed that the way they performed in practice did not match the others' expectations. Still, the students did not have the knowledge they needed so that their performance could match these expectations. Political decisions on a macro level related to the resources being distributed to the organizations where the field placements took place might be a plausible explanation for why the field instructors might have placed the students in such work situations and did not provide the students with the support they needed by explaining clearly the tasks and expectations in advance. The lack of resources could have caused situations where the field instructors had too many responsibilities and that they had to choose between prioritizing service users or prioritizing the students. If this was the case, then the main reason behind the appearance of this type of challenges was the demanding work conditions for the field instructors caused by structural conditions. The political decisions might have affected the students negatively in an indirect way. Another reason behind the existence of this type of challenges might be a very complex organizational structure in the field placements that include the staff's personal values, stereotypes, and expectations towards the students. The experience of not living up to the expectations of the field instructors and the service users lead the students to feel disappointed. Further this experience caused the students to feel that they were not being loyal towards their field instructors, and that they were not helping the service users to improve their lives but making their life conditions even worse.

Reamer (2019) writes that ethical dilemmas arise in situations when a professional social worker experiences conflicts between professional duties and obligations. To understand whether or not the social work students in our study experienced ethical dilemmas due to the structural conditions, it is important to find out if the students experienced conflicts between professional duties and obligations. A possible consequence of not getting sufficient support from the field instructors or their peers could be that the students were not able to predict the outcomes of their choices. If the students did not understand what the possible outcomes might be, it could be difficult for the students to define whether or not they were practicing in accordance with the ethical guidelines. Not knowing or being able to predict the outcomes could naturally be mentally exhausting, as the students were trying to solve situations without knowing how. The results of our analysis lead us to believe that it was the lack of support and tacit expectations that were not appropriately explained that caused the students to feel insecure and frustrated. Thus, we will argue that the structural conditions at the field placements lead to ethical challenges but these conditions were hardly causing any ethical dilemmas for the students, since they did not seem to have sufficient knowledge about the organizations they were placed in to fully understand the obligations of social workers, and the students did not seem to have in-depth knowledge about the ethical guidelines for social workers either.

Weinberg \& Banks (2019) write that social workers who in their educational programme have been trained to see moral injuries and to have integrity while working for the best of others can experience frustration at the micro-level of the work with individuals due to political systems that challenge the situations of the service users. Therefore, we agree with Weinberg \& Banks (2019) that it is necessary to understand 
the connection between politics and ethics and to actively speak out against systems that make it difficult to practice the profession in accordance with the agreed ethical principles.

Lack of knowledge and experience

The second category of the ethical challenges that our students experienced is grounded in their lack of knowledge and experience. Tallant and Ryberg (2000) state that social workers can experience ethical dilemmas when they have to choose the best moral course of action without knowing in advance the outcome of the decision. Our results show that the students experienced feelings of confusion and frustration as they realized that they did not have enough knowledge and experience to make a wellinformed choice between available alternatives.

The students did not have a good overview over possible consequences of their actions and decisions when practicing in the field. The mere intention of field placement is that social work students should get practical experience, and it seems that they are expected to choose the best moral course of action. However, the level of knowledge and experience that are required from the students to make informed choices on the best moral course of action is neither questioned nor problematized. The social work students in our study experienced ethical challenges as a consequence of their lack of experience and knowledge. The students struggled, for instance, with boundary issues in the relationships with the service users. Beate sent text messages to the service users she worked with to show that she cared for them, Christina feared that she would invade privacy of an young unaccompanied minor who was gay if she talked to him about his sexual orientation, and therefore avoided it. Frida struggled with the reaction she got from the service user she worked with at the end of the placement's period. Both Beate and Frida accepted to work at the field placements in their holidays after their periods ended partially based on their fear to end the relationships with the service users. The students were worried that setting clear boundaries would negatively affect the relationships that they had worked hard to establish. It was difficult for the students to find the correct balance between what they should share with the service users about themselves as private persons.

According to the definition of ethical dilemmas developed by Tallant and Ryberg (2000) students have high risks of experiencing ethical dilemmas just because they are novices in the field. The position of being unexperienced and not having knowledge from similar situations increases the risk of experiencing ethical dilemmas dramatically for students in field placements. We have found that lack of knowledge and experience was not problematic in cases where students in our study got sufficient support from their field instructors (for instance, when preparing for new learning situations). However, our students ended up with ethical dilemmas when field instructors did not provide the students with the support and supervision they needed. This applies especially to the cases when the students had to face very complicated situations. We argue that lack of knowledge and experience can result in ethical dilemmas for the students when the students do not get sufficient support and supervision from their field instructors.

Awareness of values

The third category of the ethical challenges that our students experienced is related to their level of awareness of values. It was difficult for our students to find an ideal balance between respecting diversity among the service users as well as maintaining their own professional integrity. The students perceived that they sometimes had set unrealistic goals for the service users, and that the expressed goals were not necessarily what the service users wanted or could achieve in their lives. Although our students put a lot of effort into creating conditions that would contribute with life improving results for the service users they worked with, the service users did not always appreciate the students' efforts or react in ways that the 
students had hoped for. On some occasions it seemed difficult for the students to accept that the decisions and perspectives of the service users that were different from what the students would have chosen themselves in such situations. This could create conflicts between the idea of achieving the goals that originally had been set and respecting that the service users have the right to change their opinions.

Respecting diversity and understanding the nature of ever-changing opinions of the service users, and thus acknowledging the service users' right to self-determination, can be challenging for the students. To comply with the service users' right to self-determination it can sometimes be necessary to accept that the initially set goals will not be reached and that there might not always be visible results when the professional relationships with the service users end. This might be a threat for the dignity of social workers in a neoliberal context where what counts as good social work practice is what is possible to measure. One of the results of our analysis is that working efficiently was one of the expectations that the students were confronted with, especially at the end of their field placements. The students experienced ethical challenges when the field instructors expected that the students managed to solve tasks faster than what the students felt comfortable with.

We argue that ethical challenges that the students experience because of better awareness of values and perspectives might result in ethical dilemmas for the students. The students in our study experienced ethical dilemmas in organizational working environments where values of efficiency and measurable results were held in high regard. A possible explanation for this might be that this value is considered to be conflicting with the values of the social work profession. The value of efficiently has been introduced by the political ideology of neoliberalism, but it is not among the values that constitute the present-day value base of the social work profession (Swift et. al, 2019).

The students might want the service users to improve in different ways for their own good, but the goals might sometimes be impossible to meet for different reasons. Accepting that the service users' goals must be reduced or changed in order to be possible to achieve can bring along feelings of failure for the students. A possible explanation to this can be that the social work students confuse their own life goals with the ones of the service users. If students are not aware of what goals or values they possess and why, service users might end up having to bear the consequences. This can happen if service users end up getting solutions or treatments not based on their own real needs but on the needs of the students (Urdang, 2010). The students in our study experienced ethical dilemmas due to unexpected reactions that occurred when the students were in direct contact with the service users. The students felt disappointed because they performed neither in accordance with their own expectations nor with the expectations from their field instructors. Dina was optimistic even when a service user did not reach the goals that they had agreed upon at first, but later she became frustrated because she understood that the goals would never be reached. Anne became aware that she had negative stereotypes that turned out to be about something else than she originally thought they were.

\section{Professional interaction with staff members}

The results of our analysis also indicate that the social work students experienced ethical challenges through interacting with staff members at their placements, our fourth category of ethical challenges. These challenges are related to the students' capacity of being critical to the practice of other staff members and being able of speaking out against unethical practice. The students found it hard to be critical towards the practice of other members of the staff when they were set to observe how these staff members behaved in direct contact with the service users. The students often found it easier to copy what others did than pointing out the staff members that certain issues should have been handled differently. 
Still, the critical awareness of the students made itself known when they witnessed what they interpreted as unethical practice. Elisabeth witnessed that her senior colleagues talked about the service users when they were not present in a negative way. Anne realized that information was being withheld from a service user in order to prevent negative reactions that the staff could have difficulty handling. Dina observed that the social workers helped the service users by doing different things for them instead of teaching the users how they could fix things themselves. Frida experienced that her field instructor and another social worker in a specific situation harmed a service user because they followed the guidelines too strictly.

The field instructors in our study openly proclaimed that the students should be open and honest about practices that they reacted to in negative ways at the field placements, but it varied how the field instructors handled the criticism that the students expressed. Sasson (2000) argues that the code of ethics gives room for interpretation when solving complicated dilemmas, but the principles must be explored and justified when compared, and such a process will be influenced by the personal values and beliefs of the social worker. In the example of Elisabeth there seems to be a contradiction with the actual practice of her colleagues, the ethical principle of recognizing the inherent dignity of every person, and Elizabeth's personal value of treating others the way she herself would like to be treated. The example of Elisabeth could have turned into an ethical dilemma if she had not talked about her experiences with her field instructor or if this one had not shared Elisabeth's view that this was the case of unethical practice. Since Elisabeth experienced that her field instructor understood the contradictions between the actual practice at the field placement and the values of the profession, she did not experience an ethical dilemma. She instead got support for her views and her field instructor included her in a discussion about how it could be possible to change such unethical practice.

\section{Experienced ethical dilemmas}

The results of our analysis show that the students have experienced ethical dilemmas due to the lack of knowledge and experience, as the result of becoming better aware of own values and due to the professional interaction with staff members. The first type of ethical dilemmas concerns growing pains of our students as professionals and is about making choices between following the will of others and marking own boundaries. The second type of the experienced ethical dilemmas is between present-day awareness of own values and perspectives and the ideal type of these values and perspectives. The third type of the experienced dilemmas are the dilemmas between being silent or speak out against the other staff members' unethical practice. Basing on the results of our thematic analysis we cannot say that unsatisfactory structural and political issues forming the working environment where the field placements took place created ethical dilemmas, but such conditions could make the field placements of social work students more complicated and difficult for the students' practice in general. Such difficulties might also reduce the students' learning outcomes.

Reamer (2019) writes that it is common for ethical dilemmas to appear in the following areas of social work: clinical practice, program design, agency administration, social policy, and relationships among practitioners. The students in our study experienced ethical dilemmas in three out of these five areas: clinical practice, agency administration and relationships among practitioners. The students reacted negatively in specific situations to other employees' social work practice. Such situations involve frustrations regarding the practice of others as well as the agency administration, since the managers can have a lot to do with how unethical practice is being handled. In some of these situations the students became frustrated about how their opinions regarding the unethical practice of others were dealt with when they raised their concerns. It is unrealistic to assume that students would be able to predict in advance the outcomes of decisions made to resolve ethical dilemmas, especially, in the beginning of their placement period. Our 
results show that the students' ethical challenges become their ethical dilemmas if the field instructors do not provide the students with sufficient support and supervision, and if the students' interpretations of the other practitioners' unethical practice remains unacknowledged and thus not discussed. The results of our analysis show that to avoid dealing with ethical dilemmas in new learning situations the students need support of their field instructors and others at the field placements to understand what ethical principles and under what circumstances might lead to a conflict.

Having mentioned this, we need to press the point that we do not believe that students must never experience ethical dilemmas in field placements. Ethical dilemmas can contribute with important learning about ethics and must hence not be considered to be completely undesirable. Still, we argue that students will learn more and get less frustrated if they get support, acknowledgement and knowledge of various risk aspects from the more experienced workers. Such support can help the students to be able to predict possible outcomes of different scenarios and thus enable the students to make choices easier and reduce possible negative consequences that the ethical dilemmas bring forth.

\section{What implications can the handling of the ethical dilemmas have for the organization of social work education?}

According to Proctor, Morrow-Howell \& Lott (1993) an ethical dilemma in social work practice is an experience a social worker has when it is not possible to practice the profession in accordance with the professional values. Thus, it is important to gain insight into values and cultures that exist in the organizations where field placements take place to predict what kind of values of the organizations that might conflict with the values of the social work profession. The insight in this area will allow an educational establishment to prepare their students for possible ethical challenges and dilemmas that these students are likely to meet in their field placements. Further, it is important to make the field instructors more knowledgeable of possible ethical challenges and dilemmas that can arise in the contexts of the organizations where these instructors work. A point of departure of what and how this insight can be created and should consist of can be discussions between educational establishments, organizations where in-field practice takes place and students.

Drawing on our findings, we argue that it is necessary to establish and maintain a good and trustful relationship between the students and their field instructors in order to avoid ethical challenges turning into ethical dilemmas. All the ethical dilemmas that our students experienced due to observing unethical practice of other staff members could have remained ethical challenges if the nature of the relationships between the instructors and the students could encourage the students without fear and hesitation to take up the challenges they had experienced. It requires much courage to speak out against unethical practices for any students as they are de facto in temporary and dependent positions in the organizations where their in-field practice takes place. If students avoid speaking out against what they interpret as unethical practice, the organizations where the field placements take place will lose valuable opportunities for improving of their services.

In any neoliberal context, where there is both a high demand for control and documentation of the services' efficiency for the users, the students' speaking out against the observed unethical practice might not be something that all in the organizations might welcome. The students in our study reported that they felt that their field instructors supported them when they told them about practices that could be understood as unethical. However, it varied what the field instructors did with the information on the unethical practices. Some instructors tried to change the unethical practices they were informed about, and some did not seem do anything to change such practices. This might be explained by the fact that the instructors did not agree 
with the students' views even though they seemed to do so, or because the instructors did not feel comfortable with bringing up the issues with their colleagues or the management.

According to the Norwegian law, social workers do not have the obligation to criticize practices that are incompatible with the code of ethics, but they have a right to notify about critical matters if practices they have witnessed are against ethical standards in a manner that can cause health injuries or death (Arbeidsmiljøløven, 2005, § 2 A-1). To notify, in this context, is understood as identifying unjustifiable, incompetent, unethical or illegal situations at the work placement and reporting such issues to someone who has the power to stop such practices (Fellesorganisasjonen, 2014). The critical situations that the students described in our study cannot be interpreted as causing health injuries or death. This means that notifying about any of such situations was not an obligatory action that the students or their field instructors had to do if from the point of view of the law.

The consequences of notifying might be serious for some of those who notifies about critical situations, and those who choose not to notify about critical matters avoid this out of fear for negative consequences (Ødegård, Trygstad \& Steen, 2016). When notifying is not legally mandatory, the students who have unsatisfactory relationships with their field instructors might choose not to notify about unethical matters, if they believe that they will not be supported. Still, the code of ethics states that social workers are accountable for their actions to the people they work with and they must work to create conditions where they minimize harm to all people. This includes notifying in the situations where practices are oppressive and unfair (Fellesorganisasjonen, 2019; IFSW, 2018).

According to the Norwegian Association of Social Workers (Fellesorganisasjonen, 2019) the loyalty of the students should be with the most vulnerable part of any ethical conflicts, in this case, the service users, as the users are more vulnerable than the systems that are supposed to help them. This means that students have a moral obligation to notify about unethical practice according to the code of ethics, and one way to accomplish this individual responsibility is to notify the field instructors. If the students notify their field instructors, they again will be morally responsible for doing something with the matters that the students have reported. Speaking out against other professionals and one's own field instructor is difficult and therefore should not become a trivialized issue in any educational program. How and when it is right for students to speak out against unethical practice needs to be furtherly discussed. Field instructors should be prepared to meet criticism from their unexperienced and often idealistic students in a constructive and supporting way, and they need to gain understanding that this might involve speaking out against the unethical practice.

There is also a risk that the students give up and learn to practice social work in a way that is not in accordance with the codes of ethics. To prevent this, we need brave field instructors who are trained in how to support the students in becoming critical agents. The educational institutions should play an important role when it comes to preparing the field instructors and the students for handling unethical practice situations. The students often do not have enough insights on relevant macro aspects to fully understand the causes of ethical dilemmas. Both identifying the reasons for why unethical practice take place, in the first place, and, secondly, pointing out where the responsibilities for unethical practices lie are the issues that the students partly can be prepared for at the educational institutions by learning about how ethical principles may conflict with each other and why. Basing on our findings, we believe that the social work students need to be educated better about situations where ethical dilemmas in field placements could occur prior to their placements. 
The students will also have to make different moral choices in such situations. The results of our study show that the students might not be able to do this successfully on their own. Thus, it is necessary that the students receive support from their field instructors or other professionals to see what the possible consequences of different choices might be at the places of the field placements. The value of discussing ethical problems in specific cases between students in small groups is high, and such participation might give the students the security they need to speak out against bad practice (Banks, 2005, p. 751). However, the best place to learn about these issues might probably be out in the field with competent field instructors since complex and realistic ethical dilemmas occur there. This means that one might consider changing the organizational structure of the professional training by allocating teaching about ethical dilemmas to the very places where these occur. This does not mean, however, that this issue should be taught only by the professionals at the field placements, but it can successfully be taught in collaboration with such professionals.

Following Nordstrand \& Skjefstad (2019), we argue that it might be fruitful to develop a group supervision construct where the students can discuss such issues with experienced social workers at their educational establishments. Such construct could be designed as an addition to the supervision construct that involves the students and their field instructors and organizations. The aim of this new group supervision construct is to be an additional learning environment where it is allowed to make mistakes and explore different approaches.

Our findings also call us to argue that the students in the in-field practice need help to identify their boundaries, understand where they should draw the line in regard to personal issues. To understand that the service users are the ones who decide on their own final goals in their lives and that they can stop a process of change whenever they want to can be connected to the process of meaning-making on differences between the self of the service users and social worker's own self. Learning about one's own self and the others are impossible without engaging oneself in both inner and outer persuasive discourses. This, in turn, requires the use of the dialogical approach when one plans the teaching activities.

Findings from the studies by Nordstrand (2017) and Beddoe (2011) highlight the necessity to practice supervision using educational concepts where relationships between a supervisor and supervisees are acknowledged. A dialogic authorial learning is one of the educational concepts where the relationships between the supervisors and supervisees are considered to be a cornerstone behind any learning. Indeed, to learn how to handle ethical challenges and dilemmas requires the use of the authorial learning practices based on the dialogical approach as this approach asks for the full acceptance of the students' ontological and axiological beliefs as the prerequisites for the learning and teaching. Another reason why the dialogical approach will be the perfect choice for organizing the teaching and learning practices on the issue of ethical dilemmas is that any professional ethical dilemma is always value-laden and to find solutions to the experienced challenges and dilemmas require the choice between values. Thus, the use of authorial learning practices dialogical approach to organize teaching and learning activities both before, during and after the in-field practice is the best choice as in its heart lies a demand to the learners (both teachers and students are considered to be learners in this approach) to both identify, recognize and challenge own values and value-laden practices.

The use of the authorial learning in the area of in-field practice should be based on the assumptions that both in-field supervisors and the students are learners with equal consciousness, i.e., their experience and points of view, no matter how little their experience is or naïve their points of view are, should be heard and reacted to. Following Matusov (2011), we argue that students' learning that happens due to supervision during the in-field placements should be understood as the student's authorship. The authorship is defined 
by Matusov (2011) as a bid for a unique creative contribution fully or partially recognized by a relevant community and by the participant him/herself (this recognition can be problematic, contested, and controversial at times). Learning is thus should be aimed at transformation of supervisees and supervisor's authorial agencies. Due to the fact that the authorial agency of any learner consists of personal attitudes, goals, values, knowledge, competences, and skills, and is a dynamic entity that goes through changes, thanks to the process of transcendence and opportunities for responsivity and dialogicality, it is important to organize supervision activities in a way that allows discussions in free and fearless environments so that the students could learn and unlearn knowledge and skills. This means that in-field placements should be viewed as learning arenas for various types of knowledge and skills, including knowledge on own selves, and not just places where the students can gain only strictly professional practical knowledge and try out their theoretical knowledge. In-field placements as learning arenas means that in-filed instructors should be allowed more engagement and contact with the students so that both the students and the instructors could experience and develop interpersonal axiology. Gradovski and Løkken (2015) write that the development of the mutual axiology is based on a mutual understanding between the supervisors and the supervisees that their values are formative in character and can and should be discussed and agreed upon, and requires that both issues of guidance and participation should be negotiated between the students and the instructors. This means that the process of the in-field practice should be re-organized and changed so that students' desires and previous knowledge are better acknowledged and appreciated.

\section{Conclusion}

Social work students can experience various ethical challenges in their field placements. If these challenges are poorly handled, they may end up becoming ethical dilemmas. Our study shows that ethical challenges become ethical dilemmas for the students if the field instructors do not provide the students with sufficient support and supervision and if the students' interpretations of other staff's unethical practice remains unacknowledged as an important issue that deserves thorough discussions. The students who participated in this study experienced ethical dilemmas due to lack of knowledge and experience, as the result of becoming better aware of own values and perspectives and due to interacting with other staff members. The areas where the students in our study experienced ethical dilemmas are well known and common for social work practice in general, and already existing theory about handling ethical dilemmas may therefore be useful for educating students.

We believe that the best place to learn about these issues might probably be out in the field with competent field instructors, since complex and realistic ethical dilemmas occur there. This means that one has to change the organizational structure of the professional training by allocating teaching about ethical dilemmas to the very places where these occur. This does not mean, however, that this issue should only be taught by the professionals in the field placements, but it can successfully be taught in collaboration with such professionals where teaching cases can be real ethical dilemmas.

The educational institutions obviously play an important role when it comes to preparing the field instructors and the students for what to do when they witness cases of unethical practice and experience ethical challenges and dilemmas due to it. The students in this study needed help to identify their own boundaries and understand where they should draw the line in professional relationships with the service users. To learn such things requires the use of authorial teaching and learning practices based on the dialogical approach as this approach asks for the full acceptance of the students' ontological and axiological beliefs as the prerequisites for the learning and teaching. Another reason why the dialogical approach will be the perfect choice for organizing teaching and learning practices on the issue of ethical dilemmas is that these are always value-laden and their solutions often require the choice between values. 
We believe that field instructors need to be trained in how to help their students to sort out boundary issues in the supervisory encounters. Learning about one's own self and others is impossible without engaging oneself in both inner and outer persuasive discourses. This, in turn, requires the use of the dialogical approach when one plans the teaching activities. The dialogical approach asks the learners to identify, recognize and challenge own values and value-laden practices. Therefore, the students need to be educated about situations where ethical dilemmas in field placements could occur prior to their placements.

When dealing with ethical challenges and dilemmas the students will have to make different moral choices, and they might not be able to do this successfully on their own. Thus, it is necessary that the students receive support and supervision from their field instructors and/or other professionals to see what the possible consequences of different choices might be at the places of the field placements. In the future it seems relevant to do research on how demanding working environments influence the relationship between social work students and their field instructors, and the learning outcomes for the students.

\section{References}

Arbeidsmiljøloven (2005). Lov om arbeidsmiljø, arbeidstid og stillingsvern m.v. (LOV-2005-06-17-62). Retrieved from https://lovdata.no/dokument/NL/lov/2005-06-17-62\#KAPITTEL 3

Banks, S. (2005). The Ethical Practitioner in Formation: Issues of Courage, Competence and Commitment. Social Work Education, 24(7), 737-753. https://doi.org/10.1080/02615470500238652

Beddoe, L. (2011). External supervision in social work: Power, space, risk, and the search for safety. Australian Social Work, 65(2), 197-213. https://doi.org/10.1080/0312407X.2011.591187

Blaikie, N. \& Priest, J. (2019). Designing social research. Third edition. Croydon: Polity Press.

Bogo, M. (2008). Field instruction in social work. The Clinical Supervisor, 24(1-2), 163-193. https://doi.org/10.1300/J001v24n01 09

Braun, V. \& Clarke, V. (2006). Using thematic analysis in psychology. Qualitative Research in Psychology, 3(2), 77-101. https://doi.org/10.1191/1478088706qp063oa

CSWE. (2015). Commission and accreditation. Commission on Educational policy. Retrieved from https://www.cswe.org/getattachment/Accreditation/Accreditation-Process/2015EPAS/2015EPAS Web FINAL.pdf.aspx

Creswell, J. W. \& Poth, C. N. (2018). Qualitative inquiry \& research design. Choosing among five approaches. Fourth edition. London: SAGE Publications Ltd.

Douglas, H. (2014). Values in social science. In N. Cartwright and E. Montuschi (Ed.), Philosophy of social science - A new introduction (p. 162-182). Oxford University Press.

Eide, S.B. (2008). Profesjonsetikkens basis. Fontene forskning, 1(08), 38-48. Retrieved from: https://fonteneforskning.no/forskningsartikler/profesjonsetikkens-basis-6.19.265333.7cfd418400?

Fellesorganisasjonen. (2014). Veileder om varsling. Retrieved from: https://www.fo.no/getfile.php/1381271547744215/Dokumenter/07\%20L\%C3\%B8nn\%20og\%20arbeidsvilk\%C3\%A5r/Aktuelle\%20publi kasjoner/13764\%20FO\%20Veileder\%20om\%20varsling.pdf 
Fellesorganisasjonen. (2019). Yrkesetisk grunnlagsdokument for barnevernspedagoger, sosionomer, vernepleiere og velferdsvitere. Retrieved from https://www.fo.no/getfile.php/13248471580893260/Bilder/FO\%20mener/Brosiyrer/Yrkesetisk\%20grunnlagsdokument.pdf

Gradovski, M. (2012). The use of the dialogue concepts from the arsenal of the Norwegian Dialogue Pedagogy in the time of postmodernism. Ethics and Education, 7(2). https://doi.org/10.1080/17449642.2012.733607

Gradovski, M., \& Løkken, I.M. (2015). Chronotopic thresholds, reflection, and transformation of supervision experiences for preschool assistants in Norwegian preschools. International Journal of Early Childhood, 47, 331-345. https://doi.org/10.1007/s13158-015-0137-x

Grønningsæter, A.B. (2013). Tid og makt - om etiske utfordringer i sosialtjenesten. Fontene forskning 2/2013, 43-54. Retrieved from https://fonteneforskning.no/pdf-15.19390.0.3.4f4b4bdf02

Hardy, T. (2019). Then and now: The history and development of social work ethics. In S.M. Marson \& R.E. McKinney (Eds.), The Routledge handbook of social work ethics and values (p. 22-27). London \& New York: Routledge.

IFSW. (2018). Global social work statement of ethical principles. Retrieved from https://www.ifsw.org/global-social-work-statement-of-ethical-principles/

Kadushin, A. \& Harkins, D. (2003). Supervision in social work. Fourth edition. New York: Columbia University Press.

Kunnskapsdepartementet (2011). Utdanning for velferd (Meld.St. nr. 13 2011-2012). Retrieved from: https://www.regjeringen.no/contentassets/ac91ff2dedee43e1be825fb097d9aa22/no/pdfs/stm2011 20120013000dddpdfs.pdf

Lingås, L.G. (1993). Etikk i sosialt arbeid fra regler til diskurs. Avhandling til dr. fil. graden. Universitet i Gøteborg, Sweden.

Matusov, E. (2011). Authorial teaching and learning. In E. J. White \& M. A. Peters (Eds.), Bakhtinian pedagogy: Opportunities and challenges for research, policy and practice in education across the globe (p.21-46). Peter Lang Publishing.

Matusov, E., von Duyke, K. \& Kayumova, S. (2016). Mapping Concepts of Agency in Educational Contexts. Integrative Psychological and Behavioral Science, 50, 420-446. https://doi.org/10.1007/s12124-015-9336-0

Matusov, E., Marjanovic-Shane, A., \& Gradovski, M. (2019). Dialogic Pedagogy and Polyphonic Research Art. Palgrave Macmillan.

Moorhead, B. \& Johnson, S. (2010). An ethical practice dilemma involving a new social work graduate: Implications for social work practice. Practice: Social Work in Action, 22(1), 45-53. https://doi.org/10.1080/09503150903521744

Nordstrand, M. (2017). Practice supervisors' perceptions of social work students and their placements an exploratory study in the Norwegian context. Social Work Education, 36(5), 481-494. https://doi.org/10.1080/02615479.2017.1279137

Nordstrand, M. \& Skjefstad, N. S. (2019). Veileder: Et kjærlig og trofast reisefølge? Om parallellveiledning av bachelorstudenter i praksis. Fontene forskning, 12(2), 46-58. Retrieved from https://fonteneforskning.no/forskningsartikler/veileder-et-kjarlig-og-trofast-reisefolge$\underline{6.19 .706350 .76 f 12 \mathrm{eb} 89 \mathrm{~b}}$ 
O’Donoghue, K. \& Tsui, M.-S. (2015). Social work supervision research (1970-2010): The way we were and the way ahead. British Journal of Social Work, 45, 616-633.

https://doi.org/10.1093/bjsw/bct115

O'Donoghue, K. (2015). Issues and challenges facing social work supervision in the twenty first century. China Journal of Social Work, 8(2), 136-149. https://doi.org/10.1080/17525098.2015.1039172

Proctor, E. K., Morrow-Howell, N., \& Lott, C. L. (1993). Classification and correlates of ethical dilemmas in hospital social work. Social Work, 38(2), 166-177. Retrieved from https://academic.oup.com/sw/article-abstract/38/2/166/1888375

Reamer, F.G. (2019). Essential ethics knowledge in social work. In S.M. Marson \& R.E. McKinney (Eds.), The Routledge handbook of social work ethics and values (p. 315-322). London \& New York: Routledge.

Sasson, S. DSW, CSW (2000). Beneficence versus respect for autonomy. Journal of Gerontological Social Work, 33(1), 5-16. https://doi.org/10.1300/J083v33n01 02

Swift, K.J., Gingrich, L.G. \& Brown, M. (2016). Social work education: The challenge of neoliberalism. In I. Taylor, M. Bogo, M. Lefevre, \& B. Teater (Eds.), Routledge international handbook of social work education (p. 382-393). Oxford \& New York: Routledge.

Søndenå, K., og Gradovski, M. (2017). Pre-tekst sin rolle i rettleiing av nyutdanna profesjonsutøvarar - ei kronotopisk analyse. UNIPED, 4/2017. https://doi.org/10.18261/issn.1893-8981-2017-04-08

Tallant, S.H., \& Ryberg, R. A. (2000). Social work in the military: Ethical dilemmas and training implications. In J.G. Daley (Ed.), Social work practice in the military (p. 179-204), New York: Haworth Press.

The Norwegian Ministry of Education and Research (2012). Utdanning for velferd. Samspill i praksis (Meld. St. 13 (2011-2012)). Retrieved from https://www.regieringen.no/no/dokumenter/meld-st13-20112012/id672836/

The University of Stavanger. (2013). Internt reglement for praksis. Institutt for sosialfag. Retrieved from https://www.uis.no/getfile.php/1391248/SV/Gjeldende\%20praksisreglement\%20ved\%20IS.pdf

Urdang, E. (2010). Awareness of Self - A Critical Tool. Social Work Education, 29(5), 523-538. https://doi.org/10.1080/02615470903164950

Vassos, S., Harms, L. and Rose, D. (2019). The value of mixing it up: Student experiences of a multimodal approach to supervision on placement. The British Journal of Social Work, 49(5), 12741295. https://doi.org/10.1093/bjsw/bcy105

Weinberg, M. \& Banks, S. (2019). Practising ethically in unethical times: Everyday resistance in social work. Ethics and Social Welfare, 13(4), 361-376. https://doi.org/10.1080/17496535.2019.1597141

Yin, R. K. (2012). Applications of case study research. California, USA: Sage.

Ødegård, A.M., Trygstad, S.C. \& Steen, J.R. (2016). Varsling og ytring blant medlemmer i sju fagforbund: Rapportserie om varsling og ytring. Oslo: FAFO. 
Ethical dilemmas in field placements Heidi Lie Eriksen, Mikhail Gradovski

\section{(cc) EY}

New articles in this journal are licensed under a Creative Commons Attribution 4.0 United States License. ULLS

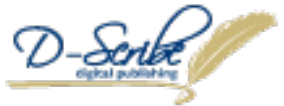

This journal is published by the University Library System, University of Pittsburgh as part of its D-Scribe Digital Publishing Program and is cosponsored by the University of Pittsburgh Press. 